\title{
Ecological Genetics of the Mussels Mytilus edulis and M. galloprovincialis on Irish Coasts
}

\author{
E. M. Gosling and N. P. Wilkins \\ National University of Ireland, University College, Galway, Ireland
}

\begin{abstract}
Genetic polymorphism at the loci encoding the enzymes phosphoglucose isomerase, leucine aminopeptidase and phosphoglucomutase was investigated in Irish Mytilus populations. Allele frequencies and heterozygote proportions indicated that populations on exposed Atlantic coasts differed from those on sheltered Atlantic coasts, and from Irish Sea mussels. When compared with data on $M$. edulis collected in northern France and $M$. galloprovincialis from the Mediterranean these data indicate that in Ireland M. galloprovincialis occurs mainly at exposed sites, and hybridization with $M$. edulis occurs frequently. The systematic status of the two forms remains uncertain in the light of genetic evidence of hybridization and intergradation between them.
\end{abstract}

\section{INTRODUCTION}

Mytilus edulis L. and Mytilus galloprovincialis Lmk. occur on the coasts of Ireland (Baird, in Hepper, 1957; Kitching et al., 1959; Ebling et al., 1960). They are not, however, evenly distributed on all coasts; Seed (1974) reported that $M$. edulis alone occurred on the Irish Sea coast, whereas both mussels were found on the South, West and North coasts. Until recently, the two mussel types were distinguished by physiological and morphological characters alone (Seed, 1971). These characters are very variable in British and Irish mussels (Lewis and Seed, 1969), and accurate identification of populations of the two types based on these characteristics is difficult, especially at exposed sites (Seed, 1974). Biochemical genetic studies have indicated that they differ also at a small number of enzyme gene loci (Ahmad and Beardmore, 1976; Gosling and Wilkins, 1977; Skibinski et al., 1978) and in addition, suggest that some hybridization may occur between the two forms on the Atlantic coasts of Ireland and parts of Britain. The extent of hybridization varies from site to site, and it has been suggested (Skibinski and Beardmore, 1979) that in some environments hybrids and individuals of mixed ancestry may have fitness superior to that of the edulis form. The results of the present study, taken in conjunction with those from our preliminary report (Gosling and Wilkins, 1977), suggest that the $M$. galloprovincialis form favours the offshore habitat and hybridization with $M$. edulis is common there; in sheltered shore environments, $M$. galloprovincialis occurs only to a very limited extent and hybrids are consequently rarer.

\section{MATERIALS AND METHODS}

Approximately 4100 individual mussels were analysed in the period since October 1974. These were collected from 26 sites on the coasts of Ireland (Table 1). Mussels were collected from two types of habitat: exposed sites, located on headlands lacking protection from wave action and prevailing winds and sheltered sites located at the inner end of inlets and bays in fully saline waters. At four sites $(2,5,17$ and 28) mussel populations were entirely sublittoral; these were classified as sheltered sites. For purposes of comparison pure samples of Mytilus galloprovincialis were analysed from Venice and Cannes on the Mediterranean coast and a single sample of $M$. edulis was analysed from San Vaast on the Channel coast of France.

Technical details of sample preparation, electrophoretic procedure and visualization of $P g i$ and $P g m$ have been described previously (Gosling and Wilkins, 1977). Staining for Lap was performed using the method of Murdock et al. (1975), but the Lap locus studied by us is not that studied by Murdock et al., nor the Lap-1 locus described in Skibinski and Beardmore (1979).

The terminology used for all allozymes is as follows: $a$ indicates the least anodal allozyme, and $b, c, d$ etc. 
Table 1 Classification of the various sampling sites on the Irish, French and Italian coasts. E: exposed site; $\mathrm{S}$ : sheltered site; $N$ : minimum number of individuals analysed for each of the 3 loci - Pgi, Lap and Pgm. Mussels from Sites 13 and 29 were not assayed for Pgm. Mussels from Sites 6,11 and 13 were not assayed for Lap

\begin{tabular}{|c|c|c|c|}
\hline Site & & Shore exposure & $\mathrm{N}$ \\
\hline \multicolumn{4}{|c|}{ IRELAND } \\
\hline \multicolumn{4}{|c|}{ East coast } \\
\hline 1 & Belfast & $\mathrm{S}$ & 142 \\
\hline 2 & Drogheda & $\mathrm{S}$ & 79 \\
\hline 3 & Baldoyle & $\mathrm{S}$ & 99 \\
\hline 4 & Dublin & $S$ & 100 \\
\hline 5 & Wicklow & $\mathrm{S}$ & 37 \\
\hline 6 & Cahore Point & $\mathrm{E}$ & 70 \\
\hline \multicolumn{4}{|c|}{ South coast } \\
\hline 7 & Wexford & $\mathrm{E}$ & 425 \\
\hline 8 & Waterford & $\mathrm{S}$ & 142 \\
\hline 9 & Cork & $\mathrm{E}$ & 73 \\
\hline 10 & Cork & $\mathrm{S}$ & 88 \\
\hline 11 & Kinsale & $\mathrm{S}$ & 59 \\
\hline 12 & Lough Ine & $\mathrm{S}$ & 162 \\
\hline 13 & Bantry & $\mathrm{S}$ & 82 \\
\hline \multicolumn{4}{|c|}{ West coast } \\
\hline 14 & Kilkee & $E$ & 96 \\
\hline 15 & Blackhead & $E$ & 194 \\
\hline 16 & Nimmo's Pier & $\mathrm{S}$ & 213 \\
\hline 17 & Lough Atalia & $\mathrm{S}$ & 198 \\
\hline 18 & Salthill & $\mathrm{S}$ & 28 \\
\hline 19 & Carna & $E$ & 76 \\
\hline 20 & Glinsk & $\mathrm{S}$ & 124 \\
\hline 21 & Killary & $\mathrm{S}$ & 1054 \\
\hline 22 & Achill & $E$ & 63 \\
\hline 23 & Donegal & $E$ & 86 \\
\hline 24 & Donegal & S & 69 \\
\hline \multicolumn{4}{|c|}{ North coast } \\
\hline 25 & Melmore Head & E & 46 \\
\hline 26 & Portrush & E & 79 \\
\hline \multicolumn{4}{|c|}{ NORTH FRANCE AND MEDITERRANEAN AREA } \\
\hline 27 & San Vaast & $\mathrm{S}$ & 92 \\
\hline 28 & Cannes & $S$ & 68 \\
\hline 29 & Venice & S & 54 \\
\hline
\end{tabular}

are used for progressively more anodal allozymes. Alleles $P g i^{i}, P g i^{d}$ and $P g i^{b}$ in this paper correspond to alleles $P g i^{A}, P g i^{B}$ and $P g i{ }^{C}$ respectively in Gosling and Wilkins (1977) and to alleles $\mathrm{Pgi}^{5}, \mathrm{Pgi}^{3}$ and $\mathrm{Pgi}^{1}$ of Ahmad and Beardmore (1976).

\section{RESULTS}

Pgi, Pgm and Lap migrated towards the anode in all individuals and multiple zones of activity were observed for each enzyme.

At the Pgi locus 7 alleles were observed in Irish populations of Mytilus. The three most common alleles were designated Pgit, Pgid and Pgi ${ }^{b}$. The less common alleles were $P g i^{i 3}, P g i^{c}, P g i^{e}$ and $P g^{i g}$. All of these, with the exception of $P g i^{a}$ and $P g i{ }^{g}$, were also observed though at different frequencies - in M. galloprovincialis from the Mediterranean area.

At the Lap locus, 3 common ( $L a p^{b}, L a p^{c}$ and $L a p^{d}$ ) and 2 rare alleles ( $L a p^{\alpha}$ and $L a p^{e}$ ) were observed in both forms. At the Pgm locus also both forms exhibited three common $\left(\mathrm{Pgm}^{b}, \mathrm{Pgm}^{c}\right.$ and $\left.\mathrm{Pgm}^{d}\right)$ and two rare alleles $\left(P_{g} m^{a}\right.$ and $\left.P g m^{e}\right)$. At each locus all alleles which exhibited a frequency $\geq 0.05$ in at least one sample were treated separately for statistical analyses. Alleles with frequencies $<0.05$ have been pooled where necessary.

\section{Irish Sea Sites}

527 individuals were analysed from 6 separate sites, all but one of which were sheltered or sublittoral. Table 2 summarizes the allele frequency data for the common alleles at each enzyme locus in these samples. Genotype proportions and allele frequency data for each of the samples analysed in the present study are available on request.

Pgi: At the Pgi locus 3 alleles $P g i^{b}, P g i^{d}$ and $P g i^{f}$ were common with mean frequencies of $0.05,0.30$ and 0.61 respectively; 2 other alleles $P g^{i^{a}}$ and $P g i^{g}$ each occurred at frequencies of approximately 0.01 . The alleles $P g i$ and $\mathrm{Pgi}^{\mathrm{c}}$ were entirely absent in these samples, all of which were in Hardy-Weinberg equilibrium with $D_{t}$ values close to $0\left(D_{1}\right.$ was calculated as $\left[\mathrm{H}_{0}-\mathrm{H}_{\mathrm{e}}\right] / \mathrm{H}_{\mathrm{e}}$, where $\mathrm{H}_{\mathrm{o}}$ is the total number of heterozygotes observed per sample, and $\mathrm{H}_{e}$ the total number expected from the estimated allele frequencies). Allele frequencies were homogeneous over all sites analysed.

Lap: At the Lap locus 3 common alleles, $L a p^{b}, L a p^{c}$,

Table 2. Mean frequencies and standard deviation of the major alleles of Pgi, Lap and Pgm in samples of mussels from Irish coastal sites. $N$ : number of sites sampled

\begin{tabular}{|c|c|c|c|}
\hline \multirow[b]{2}{*}{ Loci } & \multirow{2}{*}{$\begin{array}{c}\text { IRISH SEA COAST } \\
\text { Sheltered } \\
N=5\end{array}$} & \multicolumn{2}{|c|}{ ATLANTIC COAST } \\
\hline & & $\begin{array}{l}\text { Sheltered } \\
N=9\end{array}$ & $\begin{array}{c}\text { Exposed } \\
N=9\end{array}$ \\
\hline$P g i^{b}$ & $0.05 \pm 0.01$ & $0.05 \pm 0.02$ & $0.04 \pm 0.02$ \\
\hline$P g I^{d \alpha}$ & $0.30 \pm 0.01$ & $0.37 \pm 0.05$ & $0.44 \pm 0.06$ \\
\hline$P g i \mathrm{e}$ & $0.0 \pm 0.0$ & $0.02 \pm 0.03$ & $0.16 \pm 0.07$ \\
\hline$P g I^{t}$ & $0.61 \pm 0.02$ & $0.52 \pm 0.07$ & $0.29 \pm 0.05$ \\
\hline$L a p^{b}$ & $0.11 \pm 0.03$ & $0.10 \pm 0.02$ & $0.09 \pm 0.04$ \\
\hline Lap & $0.61 \pm 0.05$ & $0.57 \pm 0.04$ & $0.48 \pm 0.04$ \\
\hline Lap & $0.26 \pm 0.03$ & $0.30 \pm 0.07$ & $0.41 \pm 0.05$ \\
\hline$P g m$ & $0.13 \pm 0.05$ & $0.13 \pm 0.02$ & $0.14 \pm 0.04$ \\
\hline $\mathrm{Pgm}^{\mathrm{r}}$ & $0.64 \pm 0.03$ & $0.60 \pm 0.03$ & $0.57 \pm 0.04$ \\
\hline$P g m^{\mathrm{d}}$ & $0.21 \pm 0.02$ & $0.25 \pm 0.04$ & $0.28 \pm 0.04$ \\
\hline
\end{tabular}


and $L a p^{d}$ and 2 rare alleles $L a p^{d}$ and Lape were observed. The mean frequency of $L a p^{c}(0.61)$ was considerably higher than $L a p^{d}$ (mean frequency 0.26). All samples were in Hardy-Weinberg equilibrium and allele frequencies were homogeneous over localities.

Pgm: 3 common alleles $P_{g m}^{b}(\overline{\mathrm{p}} 0.13), P_{g m^{c}}(\overline{\mathrm{p}} 0.64)$ and $P g m^{d}(\overline{\mathrm{p}} 0.21)$ and 2 rare alleles $P g m^{d}$ and $P g m^{e}$ were observed at this locus. Allele frequencies were homogeneous over localities. There is no evidence at the 3 loci that the mussels in the Irish Sea constitute anything except a single panmictic population. The single exposed shore sample did not differ greatly in allele frequency from the sheltered shore samples from this area.

\section{Atlantic Coast Sites}

Approximately 3400 individuals were analysed from 9 exposed and 9 sheltered sites on the Atlantic coasts (North, West and South coasts) of Ireland. The data obtained are summarized in Table 2.

In both sheltered and exposed shore samples four common Pgi alleles $\left(P g i^{b}, P g i^{d}, P g i^{e}\right.$ and $\left.P g i^{i}\right), 3$ common Lap alleles ( $\left.L a p^{b}, L a p^{c}, L a p^{d}\right)$ and 3 common Pgm alleles $\left(\mathrm{Pgm}^{b}, \mathrm{Pgm}^{c}\right.$ and $\left.\mathrm{Pgm}^{d}\right)$ were observed. However, the frequencies of these alleles differed considerably between the 2 groups of samples.

Pgi: In sheltered sites Pgif had a mean frequency of 0.52, and Pgie - which was entirely absent from the Irish Sea sites - had a mean frequency of 0.02 . At exposed sites the mean frequency of $P g^{i}$ was significantly smaller $(\overline{\mathrm{p}} 0.29)$ and that of Pgie $(\overline{\mathrm{p}} 0.16)$ significantly greater than in sheltered sites. Within each group - exposed and sheltered - interlocality heterogeneity in allele frequency was greater than that observed in the Irish Sea samples. The majority of the sheltered shore samples were in Hardy-Weinberg equilibrium, whereas all exposed shore populations, with one exception, exhibited significant deficiencies of heterozygotes.

Lap: In sheltered sites the mean frequency of $L a p^{c}$ (0.57) was higher and.that of $\operatorname{Lap}^{d}(0.30)$ lower than in exposed shores ( 0.48 and 0.41 respectively). All samples with the exception of two sheltered shore sites were in Hardy-Weinberg equilibrium.

Pgm: The mean frequencies of the 3 common alleles were very similar in the 2 groups. In general, the frequency of $\mathrm{Pgm}^{d}$ was higher and that of $\mathrm{Pgm}^{c}$ lower than those observed in the Irish Sea samples. At 6 sites significant deficiencies of heterozygotes were observed. When the mean allele frequencies at the 3 groups of sites (Irish Sea, Atlantic sheltered and Atlantic exposed) were compared by single-factor analysis of variance, the differences between them were statistically significant ( $p<0.05$ or less) for the most common alleles at all loci. Of the 3 loci, Pgi exhibited the greatest degree of differentiation in all intergroup comparisons. The major component of the overall heterogeneity can be attributed to differences between exposed Atlantic sites and sheltered (both Atlantic and

Table 3. Frequency of $P g i e$ together with $D_{1}$ values at the Pgi locus in samples of Mytilus from exposed and sheltered sites on the Atlantic coasts of Ireland. $D_{t}=$ deviations of observed heterozygote numbers from Hardy-Weinberg expectations formulated as: $D_{1}=\left(\mathrm{H}_{0}-\mathrm{H}_{\mathrm{e}}\right) / \mathrm{H}_{\mathrm{e}}$, where $\mathrm{H}_{0}=$ total number of heterozygotes observed and $\mathrm{H}_{\mathrm{e}}=$ total number expected from the estimated allele frequencies. Site numbers in parentheses correspond to those in Table 1 . $H^{\text {inin }}$ and $H^{\text {max }}$ : minimum and maximum proportions of hybrid genotypes in each population. (See text for calculation procedure). Probability that observed genotype proportions within

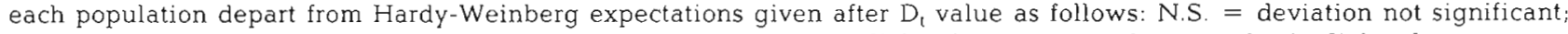
- = significant at the $5 \%$ level; $\cdots=$ significant at the $1 \%$ level; $\cdots=$ significant at the $0.1 \%$ level

\begin{tabular}{|c|c|c|c|c|c|c|c|c|c|}
\hline \multirow[b]{2}{*}{ Site } & \multirow{2}{*}{\multicolumn{2}{|c|}{$\begin{array}{c}\text { Exposed } \\
D_{1}\end{array}$}} & \multicolumn{4}{|c|}{ ATLANTIC SITES } & \multirow[b]{2}{*}{$\begin{array}{c}\text { Sheltered } \\
D_{t}\end{array}$} & \multirow[b]{2}{*}{$\mathrm{H}^{\min }$} & \multirow[b]{2}{*}{$\mathrm{H}^{\max }$} \\
\hline & & & $\mathrm{H}^{\mathrm{m} i n}$ & $\mathrm{H}^{\max }$ & Site & Pe & & & \\
\hline (7) & 0.15 & $-0.31 \cdots$ & 4.3 & 20.0 & (8) & 0.0 & $-0.29 \cdots$ & 0.0 & 0.0 \\
\hline (9) & 0.16 & $-0.17 \cdots$ & 9.6 & 25.0 & $(10)$ & 0.06 & $-0.25^{\cdots}$ & 4.9 & 9.0 \\
\hline (14) & 0.16 & $-0.33 \cdots$ & 7.6 & 11.0 & (11) & 0.02 & +0.08 N.S. & 3.4 & 7.0 \\
\hline (15) & 0.28 & $-0.17 \cdots$ & 8.0 & 25.0 & $(13)$ & 0.05 & -0.19 N.S. & 4.9 & 6.0 \\
\hline (19) & 0.13 & $-0.17 \cdots$ & 5.3 & 14.0 & $(16)$ & 0.0 & -0.10 N.S. & 0.0 & 0.5 \\
\hline$(22)$ & 0.17 & $-0.03^{*}$ & 9.5 & 25.0 & (17) & 0.01 & -0.09 N.S. & 1.0 & 2.0 \\
\hline (23) & 0.13 & $-0.30^{\cdots}$ & 5.8 & 14.0 & $(18)$ & 0.0 & -0.01 N.S. & 0.0 & 0.0 \\
\hline (25) & 0.19 & -0.09 N.S. & 6.5 & 24.0 & $(21)$ & 0.02 & -0.08 N.S. & 0.8 & 3.0 \\
\hline$(26)$ & 0.09 & $-0.38 \cdots$ & 6.7 & 11.0 & (24) & 0.06 & -0.11 N.S. & 4.3 & 9.0 \\
\hline Mean & 0.16 & -0.22 & 7.03 & 18.78 & & 0.02 & -0.11 & 2.14 & 4.05 \\
\hline S.D. \pm & 0.05 & 0.11 & 1.71 & 5.88 & & 0.02 & 0.11 & 2.06 & 3.53 \\
\hline
\end{tabular}


Table 4. Pgi, Lap and Pgm allele frequencies together with $\chi^{2}$ and $D_{1}$ values in samples of Mytilus from Lough Ine and Glinsk. $\chi^{2}$ : goodness-of-fit of observed to expected values from Hardy-Weinberg equilibrium; N.S. $=\mathrm{P}>0.05 ;{ }^{\bullet}=\mathrm{P}<0.05 ;{ }^{\cdots}=\mathrm{P}<0.01$; $\cdots=\mathrm{P}<0.001$

\begin{tabular}{|c|c|c|c|c|c|c|c|c|c|c|}
\hline \multicolumn{11}{|l|}{ Pgi } \\
\hline Lough Ine & $\mathrm{N}$ & a & b & c & d & $\mathrm{e}$ & $\mathrm{f}$ & g & $x^{2}$ & $D_{t}$ \\
\hline M. gallopr. & 162 & 0.01 & 0.07 & 0.04 & 0.45 & 0.17 & 0.24 & 0.02 & $29.2 \cdots$ & -0.22 \\
\hline \multicolumn{11}{|l|}{ Glinsk } \\
\hline M. edulis & 40 & 0.0 & 0.09 & 0.05 & 0.46 & 0.06 & 0.34 & 0.00 & 4.7 N.S. & -0.02 \\
\hline M. gallopr. & 116 & 0.0 & 0.02 & 0.06 & 0.42 & 0.24 & 0.25 & 0.00 & $49.6^{\cdots}$ & -0.22 \\
\hline \multicolumn{11}{|l|}{ Lap } \\
\hline Lough Ine & $\mathrm{N}$ & $a$ & b & $c$ & d & $\mathrm{e}$ & & & $\chi^{2}$ & $D_{t}$ \\
\hline M. gallopr. & 230 & 0.01 & 0.07 & 0.55 & 0.37 & 0.01 & & & $24.3^{\cdots}$ & -0.22 \\
\hline \multicolumn{11}{|l|}{ Glinsk } \\
\hline M. edulis & 39 & 0.0 & 0.06 & 0.51 & 0.42 & 0.0 & & & $9.6^{*}$ & -0.40 \\
\hline M. gallopr. & 124 & 0.0 & 0.14 & 0.47 & 0.38 & 0.01 & & & 6.9 N.S. & -0.15 \\
\hline \multicolumn{11}{|l|}{$P g m$} \\
\hline Lough Ine & $\mathrm{N}$ & $a$ & b & c & d & $\mathrm{e}$ & & & $x^{2}$ & $D_{t}$ \\
\hline M. gallopr. & 231 & 0.01 & 0.12 & 0.57 & 0.29 & 0.01 & & & 4.9 N.S. & -0.02 \\
\hline \multicolumn{11}{|l|}{ Glinsk } \\
\hline M. edulis & 39 & 0.0 & 0.14 & 0.54 & 0.31 & 0.01 & & & $1.2 \mathrm{~N} . \mathrm{S}$. & -0.12 \\
\hline M. gallopr. & 132 & 0.0 & 0.17 & 0.53 & 0.27 & 0.03 & & & 8.3 N.S. & -0.14 \\
\hline
\end{tabular}

Irish Sea) sites. Sheltered Atlantic sites are not identical to sheltered Irish Sea sites although the differences between them are significant for only 4 allelic comparisons and then only at the $5 \%$ level.

Three special features of the data for the Pgi locus are presented in Table 3: (a) Pgie which is entirely absent in all Irish Sea samples, both sheltered and exposed (527 individuals), occurs at a low mean frequency $(0.02)$ in sheltered Atlantic sites and at relatively high mean frequency $(0.16)$ in exposed Atlantic sites. (b) The high frequency of Pgie is positively correlated with high negative $D_{1}$ values (i. e., large deficiencies of heterozygotes) in these samples. The $D_{t}$ values in Table 3 refer to total heterozygote deficiency, not to those involving Pgie alone; they measure the extent to which the total number of heterozygotes depart from Hardy-Weinberg expectations. (c) If hybridization is taking place between the 2 types of mussel one method of estimating its amount is to calculate the frequencies of individuals heterozygous for two different alleles, each of which is common in one form of mussel but uncommon in the other. At the Pgi locus such genotypes occur at an average frequency of $7-19 \%$ on exposed Atlantic sites and at $2-4 \%$ on sheltered sites, depending on which genotypes are used in the calculation (Table 3). The minimum value is calculated using Pgi genotypes a/c, a/e, b/c, b/e, c/f, c/g, e/f and e/g alone. The maximum value includes the genotypes $\mathrm{c} / \mathrm{d}$ and $\mathrm{e} / \mathrm{d}$ which may represent either hybrids or pure Mytilus galloprovincialis heterozygotes.

At 2 sites (Lough Ine and Glinsk) mussels were found which morphologically resembled Mytilus gallo- provincialis. Because of this, allele frequency data for these samples were treated separately and are presented in Table 4. The Lough Ine sample was collected from the site at which Kitching et al. (1959), Ebling et al. (1960) and Seed (1974) had observed a high incidence $(58-77 \%)$ of $M$. galloprovincialis. At all 3 loci, allele frequencies closely resembled those characteristic of Atlantic exposed shore mussels (Table 2). A significant deficiency of heterozygotes was observed at the Pgi and Lap loci. Individuals bearing some resemblance in shell morphology to $M$. edulis were subsequently separated from this sample. These constituted approximately one third of the total sample. No statistically significant differences in allele frequencies were observed at any of the three laci between these individuals and the remainder of the sample. At the Pgi locus the 'eduls group' was in HardyWeinberg equilibrium whereas a significant deficiency of heterozygotes was observed in the remainder. The opposite was observed at the Lap locus where a significant deficiency of heterozygotes was observed only in the 'edulis group'.

In the Glinsk sample also, the mussels resembled Mytilus galloprovincialis morphologically. Allele frequencies at the 3 loci again closely resembled those characteristic of Atlantic exposed shore mussels (Table 2). A significant deficiency of heterozygotes was observed only at the Pgi locus. This sample was compared with mussels collected from the same shore but which did not obviously resemble $M$. galloprovincialis in shell characteristics. The 2 samples differed significantly at the Pgi locus and the frequency of $P g i^{e}$ 
Table 5. Pgi, Lap and Pgm allele frequencies together with $\chi^{2}$ values in samples of Mytilus edulis and M. galloprovincialis from San Vaast and Cannes (France) and from Venice (Italy)

\begin{tabular}{|c|c|c|c|c|c|c|c|}
\hline$P_{g i}$ & & $N$ & $d$ & e & $\mathrm{f}$ & Others ${ }^{\circ}$ & $\chi^{2}$ \\
\hline San Vaast & M. edulis & 92 & 0.26 & 0.0 & 0.64 & 0.10 & 5.5 N.S. \\
\hline Cannes & M. gallopr. & 80 & 0.79 & 0.13 & 0.03 & 0.05 & 1.4 N.S. \\
\hline Venice & M. gallopr & 74 & 0.87 & 0.12 & 0.0 & 0.01 & 0.4 N.S. \\
\hline Lap & & $\mathrm{N}$ & $\mathrm{b}$ & C & d & Others ${ }^{\circ}$ & $\chi^{2}$ \\
\hline San Vaast & M. edulis & 102 & 0.14 & 0.66 & 0.20 & 0.0 & 0.4 N.S. \\
\hline Cannes & M. gallopr. & 95 & 0.02 & 0.53 & 0.45 & 0.0 & $35.2^{\cdots} \cdots$ \\
\hline Venice & M. gallopr & 54 & 0.07 & 0.51 & 0.40 & 0.02 & 1.1 N.S. \\
\hline$P g m$ & & $\mathrm{~N}$ & b & c & d & Others ${ }^{\circ}$ & $x^{2}$ \\
\hline San Vaast & M. edulis & 104 & 0.12 & 0.66 & 0.22 & 0.0 & 4.3 N.S. \\
\hline Cannes & M. gallopr. & 68 & 0.10 & 0.53 & 0.34 & 0.03 & 6.5 N.S. \\
\hline
\end{tabular}

was significantly higher in the sample resembling $M$. galloprovincialis. The M. edulis sample was in HardyWeinberg equilibrium at the Pgi and Pgm loci but not at the Lap locus. The $M$. galloprovincialis sample was in Hardy-Weinberg equilibrium at the Pgm and Lap loci but not at the Pgi locus.

\section{Sites Outside Ireland}

Mussels identified morphologically as either Mytilus edulis or $M$. galloprovincialis were collected from sites in France and Italy; their allele frequency data are presented in Table 5. Contingency $\chi^{2}$ tests indicated that allele frequencies at the $P g i$ locus were significantly different in the 2 forms ( $p<0.001$ ). Pgid was the commonest allele in $M$. galloprovincialis $(\overline{\mathrm{p}}=0.83)$; the frequency of $P g i^{f}$ was high in $M$. edulis $(\overline{\mathrm{p}}=0.64)$ and extremely low in $M$. galloprovincialis $(\overline{\mathrm{p}}=0.02)$; Pgie, which was absent in $M$. edulis, occurred at a mean frequency of 0.13 in $M$. galloprovincialis. The mean frequency of $\operatorname{Lap}^{d}(0.43)$ was significantly higher $(\mathrm{p}<0.001)$ and that of $\operatorname{Lap}^{c}(0.52)$ significantly lower $(p<0.001)$ in $M$. galloprovincialis than in $M$. edulis. At the Pgm locus also allele frequencies in the two species differed significantly but only at the $5 \%$ level.

In summary, Pgi proved to be the most effective locus in differentiating samples which were identified morphologically as either pure Mytilus edulis or pure $M$. galloprovincialis. Highly significant differences $(p<0.001)$ in both genotypic and allelic distributions at this locus were observed when populations of the 2 forms were compared. The other 2 loci were not as useful in differentiating between them.

Table 6 summarizes the allele frequency data for Irish mussel populations and compares these with the data on Mytilus edulis and $M$. galloprovincialis from France and Italy. The overall resemblance of the Irish Sea and sheltered Atlantic data to those of $M$. edulis from northern France is apparent. The Atlantic exposed shore mussels, on the other hand, are very different from French $M$. edulis, and from the Irish Sea samples, and their allele frequencies at all 3 loci are intermediate to those of $M$. edulis and $M$. galloprovincialis.

Table 6. Mean frequency of the major Pgi, Lap and Pgmalleles in pure Mytilus edulis from France, in Irish coastal mussels and in pure $M$. galloprovincialis

\begin{tabular}{|c|c|c|c|c|c|c|c|c|c|c|}
\hline Mytilus edulis & $P g 1^{\mathrm{b}}$ & $P g i^{d}$ & Pgie & $P g 1^{x}$ & $L a p^{b}$ & Lapc & $L a p^{d}$ & $P g m^{\mathrm{b}}$ & $P g m^{c}$ & $P g M^{\mathrm{d}}$ \\
\hline France & 0.04 & 0.26 & 0.0 & 0.64 & 0.14 & 0.66 & 0.20 & 0.12 & 0.66 & 0.22 \\
\hline \multicolumn{11}{|l|}{ Mytilus } \\
\hline Irish Sea & 0.05 & 0.30 & 0.0 & 0.61 & 0.11 & 0.61 & 0.26 & 0.13 & 0.64 & 0.21 \\
\hline Atlantic sheltered & 0.05 & 0.37 & 0.02 & 0.52 & 0.10 & 0.57 & 0.30 & 0.13 & 0.60 & 0.25 \\
\hline Atlantic exposed & 0.04 & 0.44 & 0.15 & 0.29 & 0.09 & 0.48 & 0.41 & 0.14 & 0.57 & 0.28 \\
\hline \multicolumn{11}{|l|}{ M. gallopr. } \\
\hline Mediteranean & 0.01 & 0.83 & 0.13 & 0.02 & 0.05 & 0.52 & 0.43 & 0.10 & 0.53 & 0.34 \\
\hline
\end{tabular}




\section{DISCUSSION}

The study of genetic variation in European populations of mussels is complicated by the occurrence of two morphologically distinct forms, Mytilus edulis and M. galloprovincialis. While some authorities regard $M$. galloprovincialis as a good species, others consider it a variety of the larger $M$. edulis superspecies (see review by Lubet, 1973). Whether they are regarded as separate species or not, they do differ biochemically at a number of loci (Ahmad and Beardmore, 1976, Gosling and Wilkins, 1977 and Skibinski et al., 1978). These biochemical differences are confirmed and extended in this study and can be summarized as follows: $M$. galloprovincialis is characterised by a high frequency of $P_{g i i^{d}}$ and an intermediate frequency of Pgie. $M$. edulis is characterised by a high frequency of $P g i^{i}$ and the absence or very low frequency of Pgie. When samples of the 2 forms are compared at this locus, statistically significant differences in both genotypic and allelic proportions are observed. At the Lap and Pgm loci while both forms share the same alleles, each exhibits its own characteristic allele frequencies and these are significantly different between the two. Of the three loci analysed Pgi appears to be the most useful in differentiating between the two types of mussels. Mussels on the Irish Sea coast of Ireland exhibit allele frequencies at all 3 loci which are very similar to those of the pure $M$. edulis population collected at San Vaast and to pure samples of $M$. edulis collected elsewhere by others (Ahmad and Beardmore, 1976; Ahmad et al., 1977). This fact, together with the homogeneity in allele frequency observed throughout the Irish Sea samples and their morphological appearance, is consistent with the view (Seed, 1974) that mussels in this region constitute a single panmictic population of $M$. edulis alone

The outstanding feature of the Atlantic coast data is the marked difference observed between exposedshore mussels and those from sheltered sites. We believe that this difference reflects the occurrence in exposed shore samples of significant proportions of both Mytilus galloprovincialis and $M$. edulis, whereas M. galloprovincialis does not occur to any great extent on sheltered shores. Our reasoning is as follows: Allele frequencies, especially at the Pgi locus are significantly different between pure $M$. edulis and pure $M$. galloprovincialis (see Table 5). Samples which are mixtures of these 2 forms will exhibit intermediate allele frequencies (depending on the relative proportions in the mixture) and, in addition, will exhibit overall deficiencies of heterozygotes (the Wahlund effect) at those loci where allele frequencies differ greatly. This is precisely what is observed in Atlantic exposed shore samples. When the frequencies of the 10 major alleles are compared (Table 6), exposed-shore populations exhibit values which are either similar to those of $M$. galloprovincialis or are intermediate between $M$. edulis and M. galloprovincialis in 8 of the 10 comparisons. At the Pgi locus, where $M$. edulis and $M$. galloprovincialis differ most in allele frequencies, all the exposed shore populations exhibit relatively high frequencies of the M. galloprovincialis allele Pgie and all have statistically significant total heterozygote deficiencies. Sheltered Atlantic shore populations, on the other hand, have allele frequencies which resemble more closely those of $M$. edulis and, with only two exceptions, are all in Hardy-Weinberg equilibrium at the Pgi locus. They are not, however, identical to the $M$. edulis population of the Irish Sea (Table 2).

We reject the hypothesis that the genetic differences observed between exposed and sheltered shore mussels are due to selection for the following reasons: Mussels from the single exposed shore site sampled on the Irish Sea coast did not differ appreciably in allele frequency from the sheltered shore samples, and did not exhibit deficiencies of heterozygotes at the Pgi locus. In the two sheltered Atlantic sites, i. e., L. Ine and Glinsk where the mussels resembled Mytilus galloprovincialis in morphological features, and at one of which ( $L$. Ine) M. galloprovincialis has been confirmed by a number of independent authors, the allele frequencies and genotype proportions resemble exposed rather than sheltered shore mussels. Finally, if selection is acting against heterozygotes in exposed shore populations, a greater deficiency of heterozygotes might be expected among larger (older) individuals than in smaller (younger) individuals. In our earlier report (Gosling and Wilkins, 1977) we showed that heterozygote deficiency at the Pgi locus is neither correlated with absolute nor relative size of individual mussel nor is it correlated with position of the mussels on the shore, i. e., mussels in the higher, more exposed regions of the shore do not differ in allele frequency or genotype proportions from samples collected sublittorally in the same area.

The factors which result in the virtual absence of Mytilus galloprovincialis from most of the sheltered shore sites are at present unknown, as are those which exclude it from the Irish and British coasts (Seed, 1974; Skibinski and Beardmore, 1979) of the Irish Sea. Indeed, genetic evidence shows that in Britain $M$. galloprovincialis occurs only along the Cornish peninsula, the extreme north and north east of Scotland and along the caast of Yorkshire (Skibinski and Beardmore, 1979). It would be valuable to know whether these represent the more exposed of the sites sampled in Britain.

On the coasts of Ireland and Britain, the 2 forms are not easily distinguished morphologically. Features 
normally confined to one or other of the forms often occur together in single individuals, and intermediate forms occur commonly, making accurate identification difficult and sometimes impossible. Difficulties of this nature have been experienced by Lewis and Powell (1961), Seed (1974), Ahmad and Beardmore (1976) and by us in this study. An explanation for this high degree of morphological intermediacy may lie in hybridiza. tion and introgression between the 2 forms. Skibinski and Beardmore (1979) have indicated that hybridization and introgression occur at certain localities and the degree of intergradation differs from locality to locality. We have observed that hybrid genotypes occur at frequencies of about $7 \%$ in exposed shore samples and at $2 \%$ in those from sheltered sites. Our results indicate that hybridization occurs at all exposed shore sites on the Atlantic coasts of Ireland and is not restricted to a small number of isolated localities. Whether the 2 forms should continue to be regarded as good biological species despite the evidence for such extensive hybridization and integradation (Skibinski and Beardmore, 1979) is doubtful. Indeed, when they are compared at a total of 13 loci, and the extent of their genetic identity is computed, the value obtained is similar to the mean value obtained in comparisons of subspecies of other taxa (Skibinski et al., 1980).

Acknowledgements. We thank B. Ashe, B. Beatty and M. Staunton for technical assistance and all those who helped in the collection of samples. We thank Professor Pierre Lubet, Université de Caen, Normandy, France for the generous use of the facilities in his laboratory. This research was supported by a grant from the National Board of Science and Technology, Ireland

\section{LITERATURE CITED}

Ahmad, M., Beardmore, J. A. (1976). Genetic evidence that the 'Padstow Mussel' is Mytilus galloprovincialis. Mar Biol. 35: 139-147
Ahmad, M., Skibinski, D. O. F., Beardmore, J. A. (1977). An estimate of the amount of genetic variation in the common mussel Mytilus edulis. Biochem. Genet. 15: 833-846

Ebling, F. J., Sleigh, M. A., Sloane, J. F., Kitching, J. A. (1960). The ecology of Lough Ine. VII. Distribution of some common plants and animals of the littoral and shallow sublittoral regions. J. Ecol. 48: 29-53

Gosling, E. M., Wilkins, N. P. (1977). Phosphoglucoisomerase allele frequency data in Mytilus edulis from Irish coasta] sites: its ecological significance. In: Keegan, B. F., O'Ceidigh, P., Boaden, P. J. S. (eds) Biology of benthic organisms. Pergamon Press, London, pp. 297-309

Hepper, B. T. (1957). Notes on Mytilus galloprovincialis in Great Britain. J. mar. biol. Ass. U. K. 36: 33-40

Kitching, J. A., Sloane, J. F., Ebling, F. J. (1959). The ecology of Lough Ine. VIII. Mussels and their predators. J. Anim. Ecol. 28: 331-341

Lewis, J. R., Powell, H. T. (1961). The occurrence of curved and ungulate forms of the mussel Mytilus edulis $\mathrm{L}$. in the British Isles, and their relationship to $M$. galloprovincialis (Lmk.). Proc. zool, Soc. Lond. 137: 583-598

Lewis, J. R., Seed, R. (1969). Morphological variations in Mytilus from S. W. England in relation to the occurrence of Mytilus galloprovincialis. (Lmk.). Cah. Biol. Mar 10: $231-253$

Lubet, P. (1973). Exposé synoptique des données biologiques sur la moule Mytilus galloprovincialis. Synop. FAO 88: $1-8$

Murdock, E. A., Ferguson, A., Seed, R. (1975). Geographical variation in Lap in Mytilus edulis from the Irish coasts. J. exp. mar. Biol. Ecol. 19: 33-41

Seed, R. (1971). A physiological and biochemical approach to the taxonomy of Mytilus edulis and $M$. galloprovincialis from S. W England. Cah. Biol. Mar. 12: 291-322

Seed, R. (1974). Morphological variations in Mytilus from the Irish coasts in relation to the occurrence and distribution of Mytilus galloprovincialis. Cah. Biol. Mar. 15: 1-25

Skibinski, D. O. F., Ahmad, M., Beardmore, J. A. (1978). Genetic evidence for naturally occurring hybrids between Mytilus edulis and Mytilus galloprovincialis. Evolution 32: $354-364$

Skibinski, D. O. F., Beardmore, J. A. (1979). A genetic study of intergradation between Mytilus edulis and Mytilus galloprovincialis. Experientia 35: 1442-1444

Skibinski, D. O. F., Cross, T. F., Ahmad, M. (1980). Electrophoretic investigation of systematic relationships in the marine mussels Modiolus modiolus L., Mytilus edulis L., and Mytilus galloprovincialis Lmk (Mytilidae; Mollusca). Biol. J. Linn. Soc. 13: 65-73 